\title{
Editorial
}

\section{Entre conquistas e perdas, nosso adeus à mestra}

A Paidéia (Ribeirão Preto) tem muito o que comemorar nesse ano de 2007. Registramos nossa satisfação em saber que a revista foi aceita no Scientific Eletronic Library Online (SciELO). O esforço empreendido pelo Corpo Editorial, somado ao trabalho da equipe que o compõe, resultou nessa conquista coletiva que deve ser dividida também com os consultores, autores e leitores, o apoio do Conselho Nacional de Desenvolvimento Científico e Tecnológico (CNPq) e do SIBI - Sistema Integrado de Bibliotecas.

A Scientific Electronic Library Online - SciELO (www.scielo.br) é uma biblioteca eletrônica virtual que abrange uma coleção selecionada de periódicos científicos brasileiros. A SciELO é o resultado de um projeto de pesquisa da Fundação de Amparo à Pesquisa do Estado de São Paulo (FAPESP), em parceria com o Centro Latino-Americano e do Caribe de Informação em Ciências da Saúde (BIREME). A partir de 2002, o Projeto passou a contar com o apoio do Conselho Nacional de Desenvolvimento Científico e Tecnológico (CNPq). O Projeto tem por objetivo o desenvolvimento de uma metodologia comum para a preparação, armazenamento, disseminação e avaliação da produção científica em formato eletrônico. O objetivo é dar visibilidade e tornar acessível a produção científica brasileira e incentivar a consulta a essas publicações. Para tanto, implementou-se uma biblioteca eletrônica que proporciona um amplo acesso a coleções de periódicos, com seus fascículos e textos completos dos artigos. A fim de agilizar a consulta e a visibilidade da publicação, além do acesso pela lista de periódicos na SciELO, é possível consultar a revista a partir de sua home page no endereço: http:/ /www.scielo.br/paideia.

Deve-se salientar o intenso esforço de todo o Corpo Editorial para responder de modo apropriado à demanda crescente de artigos que a revista tem recebido, dando visibilidade às pesquisas das áreas da Psicologia, Educação e afins, visando contribuir para o avanço do conhecimento.
Prosseguindo no compromisso de divulgar a produção científica qualificada, disponibilizamos ao público leitor o presente fascículo.

Seguem-se os 11 artigos, divididos em sessão teórica, com seis trabalhos, e a de pesquisa empírica, com cinco artigos. O primeiro artigo, intitulado $\mathrm{Psi}$ cologia Positiva: uma nova abordagem para antigas questões, de Simone dos Santos Paludo e Sílvia Helena Koller, da Universidade Federal do Rio Grande do Sul, é um estudo teórico sobre a perspectiva da Psicologia Positiva, que visa oferecer nova abordagem às potencialidades e virtudes humanas, colocando em relevo as condições e processos que contribuem para a prosperidade dos indivíduos e comunidades.

O segundo artigo, intitulado $A$ Família e a Escola como contextos de desenvolvimento humano, de Maria Auxiliadora Dessen e Ana da Costa Polônia, da Universidade de Brasília, traz uma contribuição teórica valiosa para a promoção do desenvolvimento humano, enfatizando suas implicações nos processos evolutivos, que permitem compreender o papel desempenhado pelas configurações e vínculos familiares, bem como pela rede social de apoio no ciclo vital da família. O estudo focaliza também as funções da escola e sua influência nos indivíduos em processo de desenvolvimento, apontando algumas inter-relações entre as instituições - escola e família.

Em seguida, o artigo Temperamento, comportamento e experiência dolorosa na trajetória de desenvolvimento da criança, da autoria de Vivian Caroline Klein e Maria Beatriz Martins Linhares, da Universidade de São Paulo, apresenta uma revisão de estudos sobre as relações existentes entre temperamento, comportamento e experiências dolorosas iniciais nas trajetórias de desenvolvimento, focalizando as crianças nascidas prematuras.

O próximo artigo intitula-se Falsas Memórias: questões teórico-metodológicas, de Cíntia Marques Alves e Ederaldo José Lopes, da Universidade Fede- 
ral de Uberlândia. O trabalho apresenta uma revisão histórica desse fenômeno, precisando alguns modelos teóricos e suas contribuições para a compreensão do tema. Segundo os autores, trata-se de um assunto de interesse dos psicólogos, principalmente aqueles que trabalham diretamente com a memória das pessoas.

$\mathrm{O}$ artigo Unsicherheit do século XXI: o ensino e aprendizagem da leitura e da escrita em língua portuguesa em São Paulo, de Nilce da Silva e Patrícia Claudia da Costa Fridman, da Universidade de São Paulo, tem como objetivo discutir os processos de ensino e aprendizagem da leitura e escrita em língua portuguesa, utilizados na atualidade em São Paulo. O estudo está assentado nos conceitos de D. W. Winnicott e descreve, com base nos postulados de Bauman, a sociedade contemporânea, com seus princípios e valores enraizados na chamada "modernidade líquida", que interferem no resultado das relações pedagógicas e do ensino e aprendizado da língua portuguesa.

A pré-história da noção de causa em Freud, artigo de Roberto Calazans e Jorge Luís Gonçalves dos Santos, da Universidade Federal de São João del Rei, traz uma análise da pré-história do conceito de causalidade em Freud, desde seus estudos realizados com Charcot, em 1885, até a publicação da obra A interpretação dos sonhos, de 1900, com repercussões importantes para a reflexão sobre a problemática da causa em Psicanálise.

Na seqüência apresentamos um bloco de artigos que relatam os resultados de pesquisas empíricas. No artigo Escala de atitudes face ao lazer em adolescentes e jovens adultos, Teresa Freire, da Universidade do Minho (Portugal) e Carla Fonte, da Universidade Fernando Pessoa (Portugal), introduzem o tema do lazer, que tem sido alvo de interesse de pesquisas em Psicologia Social. O objetivo do estudo foi adaptar uma escala construída para avaliar as atitudes face ao lazer, a Leisure Attitude Scale, de Raghb e Beard, para Portugal. Os resultados permitiram concluir pela ade- quação da escala como instrumento de medida das atitudes face ao lazer, no contexto português.

$\mathrm{O}$ artigo intitulado Imprevisibilidade familiar e suas implicações no desenvolvimento individual e familiar, de Madalena Alarcão e Maria Filomena Gaspar, da Universidade de Coimbra (Portugal), apresenta as implicações da falta de consistência dos padrões de comportamento familiar e dos sistemas de regulação familiar, que origina o construto da “imprevisibilidade familiar". Esse construto permite apreender o modo como a família exerce o seu papel e poder executivo, podendo favorecer ou não perturbações do desenvolvimento familiar e do próprio indivíduo. $\mathrm{O}$ artigo apresenta um estudo de validação de um instrumento - a Family Unpredictability Scale (FUS), de Lisa Ross e Elizabeth Hill, para Portugal.

$\mathrm{O}$ artigo Opiniões dos adolescentes do ensino médio sobre o relacionamento familiar e seus planos para o futuro, de Elisângela Maria Machado Pratta e Manoel Antônio dos Santos, da Universidade de São Paulo, teve por objetivo levantar pontos positivos e negativos do relacionamento familiar segundo a opinião de adolescentes usuários e não usuários de substâncias psicoativas, bem como identificar seus planos de futuro. Os resultados mostraram que os adolescentes destacaram pontos positivos e negativos do relacionamento familiar, particularmente aspectos referentes à "dinâmica familiar". Ambos os grupos apresentaram como planos para o futuro questões referentes à família e à preparação e atuação profissional.

O estudo Atuação de professores do ensino itinerante face à inclusão de crianças com baixa visão na educação infantil, de Maria Júlia Canazza Dall'Acqua, da Universidade Estadual Paulista, traz uma contribuição oportuna no momento atual, em que tanto se tem discutido a respeito da inclusão de alunos com necessidades educacionais especiais em escolas regulares. O artigo elege como foco de análise as implicações da formação continuada de pro- 
fessores, com o objetivo de investigar aspectos relativos às necessidades de duas professoras itinerantes, participantes de um programa de formação voltado para o acompanhamento de alunos com baixa visão.

Finalmente, o artigo intitulado Programa de treinamento de consciência fonológica para crianças surdas bilíngües, de Érika Costa de Souza e Heloisa Helena Motta Bandini, da Universidade Estadual de Ciências da Saúde de Alagoas, analisa um Programa de Treinamento de Consciência Fonológica em crianças surdas, considerando que a consciência fonológica é um dos pré-requisitos básicos para a aquisição de leitura e escrita. Foram verificados efeitos positivos nos níveis de consciência fonológica dessas crianças após o treinamento, sugerindo que essa estratégia pode aprimorar o desenvolvimento da consciência fonológica em crianças surdas usuárias de língua de sinais.

O fascículo se encerra com a seção Notícias de Congresso e com as Normas de publicação.

Também comemoramos a manutenção da classificação Nacional $A$ pelo sistema de avaliação da Coordenação de Aperfeiçoamento de Pessoal de Nível Superior (CAPES) e pela Associação Nacional de Pesquisa e Pós-graduação em Psicologia (ANPEPP).

Mas 2007, infelizmente, não foi apenas um ano de conquistas, mas também de dolorosa perda, pontuando o quanto a vida é feita de encontros e despedidas. Em meio ao processo de preparação deste fascículo e antes que pudesse ver o sonho realizado da disponibilização dos fascículos na SciELO, perdemos nossa Editora, Profa. Dra. Zélia Maria Mendes Biasoli-Alves. Assim, tivemos que nos despedir de uma das maiores pesquisadoras em Psicologia do Desenvolvimento do Brasil. Nesse momento de profunda comoção pela perda precoce de nossa mestra, temos o consolo gratificante de homenagear essa grande professora, orientadora, colega e amiga. Manter na memória suas realizações é um conforto, na medida que nos permite perceber o quanto ela permanece ainda viva no seu trabalho brilhante frente à Paidéia, nas lições aprendidas pelos alunos que tiveram a oportunidade de desfrutar de seus ensinamentos e nas reflexões que enriqueceram aqueles que tiveram o privilégio de, com ela, manter um debate científico. Com sua atitude sábia e firme, enriqueceu a formação de inúmeros pesquisadores, contribuindo para o desenvolvimento científico da Psicologia no país com seu trabalho como orientadora e coordenadora do Programa de Pós-graduação em Psicologia da FFCLRPUSP, local de florescimento desse periódico.

Seu percurso foi marcado por uma visão percuciente sobre a produção do conhecimento em Psicologia, sempre desbravando caminhos e abrindo novas frentes. Também foi uma vitoriosa no desempenho de funções administrativas. Em sala de aula demonstrava a agudeza de seu raciocínio. Como professora era evidente o quanto sentia satisfação em ensinar. Poucas pessoas sabiam que também era formada em Direito e, talvez por isso, nos encantava com sua capacidade de argumentação. Suas opiniões e posicionamentos decisivos certamente nos farão falta nesse tempo que vivemos, de tão escassa densidade moral e ética nos escalões do serviço público. Seu exemplo de dedicação ao trabalho e sua linha de conduta íntegra continuará nos inspirando, pois agora temos a responsabilidade de continuar o seu legado. Esperamos fazer jus à sua liderança.

Profa. Dra. Zélia Maria Mendes Biasoli-Alves (1945-2007), com sua incrível capacidade de trabalho colocada em defesa dos ideais de uma universidade pública de excelência, foi uma das maiores responsáveis pelas conquistas de que hoje desfrutamos. Nós, seus colegas do Departamento de Psicologia e Educação da FFCLRP-USP, que testemunhamos sua luminosa trajetória, presenciamos o quanto ela soube povoar de beleza e poesia tudo aquilo que suas mãos generosamente tocavam. Mulher de fibra, visionária e semeadora de vida, era nossa raiz. Como sobreviver sem a sua seiva? Talvez do único modo possível: buscando na saudade que ficou um incentivo para prosseguirmos a tradição de luta e dedicação que nos foi legada. E agradecendo a ela pela intensa, calorosa e apaixonada convivência. A ela, sempreviva, o nosso eterno reconhecimento.

Manoel Antônio dos Santos 